Western University

Scholarship@Western

MacDonald Franklin OSI Research Centre

7-2009

\title{
Post-traumatic stress disorder and health problems among medically ill Canadian peacekeeping veterans
}

Don Richardson

Western University, Don.Richardson@sjhc.london.on.ca

Jordan Pekevski

University of South Dakota

Jon D Elhai

University of South Dakota

Follow this and additional works at: https://ir.lib.uwo.ca/osircpub

Part of the Psychiatric and Mental Health Commons

Citation of this paper:

Richardson, Don; Pekevski, Jordan; and Elhai, Jon D, "Post-traumatic stress disorder and health problems among medically ill Canadian peacekeeping veterans" (2009). MacDonald Franklin OSI Research Centre. 38.

https://ir.lib.uwo.ca/osircpub/38 


\title{
Post-traumatic stress disorder and health problems among medically ill Canadian peacekeeping veterans
}

\author{
J. Don Richardson, Jordan Pekevski, Jon D. Elhai
}

\begin{abstract}
Objective: The aim of the present study was to examine the relationship between posttraumatic stress disorder (PTSD) symptom severity and four significant health conditions (gastrointestinal disorders, musculoskeletal problems, headaches, and cardiovascular problems).

Method: Participants included 707 Canadian peacekeeping veterans with service-related disabilities, from a random, national Canadian survey, who had been deployed overseas. Results: PTSD severity was significantly related to gastrointestinal disorders, musculoskeletal problems, and headaches, but not to cardiovascular problems. Controlling for demographic factors did not affect PTSD's relationships with the three significant health conditions.

Conclusions: The present study supports previous work in finding consistent relations between PTSD severity and specific types of medical problems.

Key words: Health, military veterans, post-traumatic stress disorder.
\end{abstract}

\section{Australian and New Zealand Journal of Psychiatry 2009; 43:366-372}

Peacekeeping operations, especially in war zones, are associated with both psychiatric and physical health problems. Post-traumatic stress disorder (PTSD) is one of the significant psychiatric conditions resulting from exposure to peacekeeping operations in war zones [1,2]. Little research has been conducted, however, on PTSD's association with specific physical health problems among veterans, especially those who served as military peacekeepers. The few studies that have examined the relationship between physical health and PTSD have not con-

J. Don Richardson, Consultant Psychiatrist, Adjunct Professor (Correspondence)

Operational Stress Injury Clinic, Parkwood Hospital, St Joseph's Health Care London, University of Western Ontario, 801 Commissioners Road East, London, Ontario N6C 5J1, Canada. Email: don.richardson asjhc.london.on.ca

Jordan Pekevski, Clinical Psychology Trainee; Jon D. Elhai, Associate Professor

Disaster Mental Health Institute, University of South Dakota, Vermillion, South Dakota, USA

Received 29 July 2008; accepted 29 October 2008. trolled for relevant demographic factors related to health status.

Many studies have indicated an association between PTSD and physical health, documented in both civilian and military populations [3-9]. In fact, PTSD is related to particular types of health problems, including arterial/circulatory/heart problems $[3,4,6,9$ 12], gastrointestinal disorders $[3,6,9,10,13]$, musculoskeletal problems $[3,6,7,10,11]$, respiratory problems $[3,9,11]$, dermatological problems [6,13], endocrine/ metabolic problems [3,10], neurological/nervous system disorders [3,11], and pain problems/fibromyalgia $[7,9,10,13]$.

Physical health problems can be chronic among trauma victims $[3,11]$. Furthermore, PTSD is associated with worse health even when possible confounding variables are statistically controlled. The few studies adjusting for such variables controlled for race, ethnicity, age, education, socioeconomic status, medication use, substance abuse, hypochondriasis, 
illness onset, enlistment status, army medical profile, and combat exposure $[3,6,7,9,14]$.

Given previous research that found an association between PTSD and physical health problems, the purpose of the current study was to further examine the association between PTSD and physical health specifically in a national sample of post-1990, war zone-deployed peacekeeping veterans. In the 1990s due to increased instability to the international stage and a rise in intrastate conflicts, ethnic cleansing and global terrorism, the United Nations Security Council established more complex peacekeeping missions and traditional peacekeeping changed to more closely resemble traditional warfare [15]. Peacekeeping operations can be extremely stressful and traumatic, unique relative to other forms of combat exposure because peacekeeping requires impartiality and restraint from using force [16]. Although we would not expect to see a different pattern of health problems emerging from this type of peacekeeping operations, studying peacekeeping veterans' psychiatric and physical health is especially important because peacekeepers constitute a significant military population and Veterans Affairs provides health-care benefits and other resources to those veterans with serviceconnected disabilities. This study examined the relationship between PTSD and specific health problems both before and after controlling for demographic variables.

\section{Method}

\section{Participants}

This study used archival data collected in 1999 from Veterans Affairs Canada (VAC). In this data set, Canadian peacekeepers consisted of Canadian soldiers who were trained for combat as regular soldiers, selected to be deployed as peacekeepers depending on their qualifications (e.g. radio, artillery) and the needs of the United Nations (UN) Department of Peacekeeping Operations (DPKO). VAC sent out (by postal mail) anonymous, self-administered batteries of questionnaires to a sample of 2760 potential participants in 1999 (with research ethics board approval). A letter describing the survey was included, with veterans informed that their completion and return of the materials would imply consent. The 2760 potential participants were randomly selected and nationally stratified from a larger database of 18443 individuals (age $<65$ years) who had been identified with health conditions after serving in the Canadian armed forces, and were therefore either receiving or eligible for a disability pension from VAC [17]. A total of 1968 participants anonymously returned the completed batteries of questionnaires, resulting in a response rate of $71.30 \%$ (1968/2760). Out of these 1968 participants, 784 had been deployed overseas as peacekeepers during the 1990-1999 era (when traditional peacekeeping changed to more recent peacemaking missions), and were considered for the present study. We also decided not to exclude women in the present study because the survey is a nationally representative sample of Canadian veterans with health problems. Although in the past women usually did not serve in peacekeeping roles, in the post-1990 era this has changed in Canada and other parts of the world. To exclude women would make the sample less representative of the Canadian peacekeeping population and it also makes the sample more homogenous and thus less diverse.

Due to substantial missing data, 66 participants were removed from analysis. These 66 participants were removed from the study mostly due to missing more than $20 \%$ of items on the continuous measures. Due to inconsistent data regarding the deployment status of 11 veterans, these individuals' data were also removed from analyses. These exclusions resulted in a total of 707 participants included in the present study. There is no information on those individuals who chose not to participate in the survey, and therefore it cannot be concluded whether these individuals differed significantly from the participants in this study on any demographic variable.

\section{Procedure}

An anonymous battery of questionnaires was sent to potential participants. This battery included surveys measuring demographic variables, military service, health service use, and a standardized measure for PTSD (PTSD checklist).

\section{Instruments}

\section{Demographic information}

The demographic survey enquired about a number of demographic variables. For the present study, we utilized continuous variables including age, length and number of deployments, and categorical variables including gender $(\operatorname{coded}$ male $=1$, female $=2$ ), income (in increments of \$CAD 10000), and marital status (coded married $=1$, unmarried $=2$ ). Thirty-five theatres were presented for the 'deployment theatres' question, and an 'other' option was given in order to cover any theatres not listed.

\section{PTSD Checklist-Military Version}

The PTSD Checklist-Military Version (PCL-M) is a self-report measure that is based on DSM-IV PTSD symptom criteria. It contains 17 items, using a 5 point Likert response format $(1=$ not at all to $5=$ extremely). The PCL-M assesses the extent to which PTSD symptoms related to any stressful military experience have been experienced over the previous month. The total severity score was used, frequently reported with military samples for the purpose of establishing PTSD caseness [18-20]. Individuals with a score of $\geq 50$ on the PCL-M were placed in the PTSD Present category, and individuals with a score of $\leq 49$ on the PCL-M were placed in the PTSD Absent category. The PCL-M has adequate test-re-test 
reliability and convergent validity with several other PTSD measures. During a 2-3 day re-test interval, the PCL-M yielded test-re-test reliability of 0.96 [21]. Convergent validity (based on correlational analyses) was 0.93 with the Mississippi Scale for Combat-Related PTSD, 0.90 with the Impact of Event Scale, and 0.77 with the MMPI-2's PK scale $[21,22]$.

\section{Health Status Measure}

The health status measure was a self-report survey enquiring whether participants were diagnosed by a health professional as having a long-term physical health problem (i.e. 'This question is about long-term physical health problems. Do you have any of the following long-term conditions that have been diagnosed by a health professional?'). Participants were instructed to answer 'yes' or 'no' to 21 different health problems that were presented. For the purpose of the present study these health problems were coded into four broader categories: gastrointestinal (stomach and/or intestinal ulcers), cardiovascular (high blood pressure, and/or heart disease), musculoskeletal (arthritis, rheumatism, and/or back problems), and headaches (migraine headaches). Three other categories were considered, including endocrine and respiratory problems, and cancer, but were endorsed by too few participants for meaningful analysis.

\section{Analyses}

SPSS 15 (SPSS, Chicago, IL, USA) was used for the analyses. We used maximum likelihood estimation to estimate missing values for remaining participants with nominal amounts of missing continuous variable scores. Four sequential, bivariate logistic regression analyses were used to assess individual relationships between PTSD and the four health conditions separately. Next, to control for demographics, demographic factors were used as covariates in step 1 of a subsequent set of analyses (age, gender, income, marital status, length of deployment, and number of unique deployments) in order to determine the incremental contribution of variance from PTSD in step 2 in explaining variation in health status. As in the first set of analyses, four additional sequential logistic regression analyses were performed, but in multivariate rather than bivariate analyses. Pseudo- $\mathrm{R}^{2}$ (Nagelkerke's) values are presented in each analysis as a means of estimating the variance accounted for in the dependent variable.

A family-wise alpha level of 0.05 was used. Holm's step-down correction was used in order to control for Type I error. This correction is based on the Bonferroni correction, but is more efficient in balancing Type I and Type II error than the often too conservative Bonferroni correction [23]. In this correction, $p$ values are ranked from smallest to largest, after which the smallest $p$ value is evaluated against an alpha of 0.05 divided by the number of tests conducted (k). Subsequent $\mathrm{p}$ values are compared to a modified alpha level of $0.05 / \mathrm{k}$, in which $\mathrm{k}$ is the number of remaining tests [24].

A power analysis, albeit based on linear regression, was performed. In order to detect a medium size effect $\left(R^{2}=0.13\right)$ with power of 0.80 , alpha of 0.05 , and eight predictor variables (which included sociodemographic characteristics discussed below), 109 subjects would be needed. In order to detect a small effect size
$\left(\mathrm{R}^{2}=0.024\right)$ using the same parameters, 610 subjects would be needed. Therefore, it was determined that this study had enough participants to detect a small effect size for the analyses that did not control for demographics, and a medium effect for the analyses that did control for demographics. But we should note that this power analysis was based on linear regression, because methods for calculating power for logistic regression are not easily available.

\section{Results}

\section{Participant characteristics}

Participants $(\mathrm{n}=707)$ ranged in age from 20 to 65 years old, with the mean age being $44.87(\mathrm{SD}=9.710)$. The sample was $95.6 \%$ male $(\mathrm{n}=676)$ and $4.2 \%$ female $(\mathrm{n}=30)$, with $0.1 \%$ not indicating gender $(\mathrm{n}=1)$. Annual income ranged from $<$ \$CAD10 000 to $>$ \$CAD80000, with most participants falling in the \$CAD30000 39999 category $(16.7 \%, \mathrm{n}=118)$, followed by the \$CAD40000$49999(15.8 \%, \mathrm{n}=112)$, and \$CAD50 000-59 $999(12.4 \%, \mathrm{n}=88)$ ranges. The majority of participants reported being currently married or common law married $(83.5 \%, \mathrm{n}=590)$. The remaining participants were primarily single $(16.1 \%, \mathrm{n}=114)$.

The number of years served in the military ranged between 0 and 45 , with the average being 19.24 years $(\mathrm{SD}=10.50)$. The range of unique deployments was between one and five, with a mean of 1.61 $(\mathrm{SD}=0.79$ ). Most participants were deployed to Cyprus (TurkishGreek Cypriot conflict; $n=462,65 \%$ ), followed by the former Yugoslavia (Balkan conflicts; $\mathrm{n}=301,43 \%$ ), and Egypt (Middle East conflict; $\mathrm{n}=158,22 \%$; percentages do not add to $100 \%$ because some participants served in more than one peacekeeping operation). Table 1 provides a summary of these results.

\section{PTSD and specific health problems}

Based on a cut-off score of 50 on the PCL-M, $60 \%$ of participants were classified as having PTSD. There were no significant differences between participants with and without PTSD on the presence of any physical health problems. The mean PCL score was $30.82(\mathrm{SD}=16.73)$. PTSD symptom severity was significantly related to gastrointestinal disorders $\left(\chi^{2}(1, \mathrm{n}=\right.$ $\left.699)=21.84, \quad \mathrm{p}=0.00, \quad \mathrm{R}^{2}=0.06\right), \quad$ musculoskeletal problems $\left(\chi^{2}(1, \mathrm{n}=705)=12.01, \quad \mathrm{p}=0.00, \quad \mathrm{R}^{2}=0.02\right), \quad$ and headaches $\left(\chi^{2}(1, \mathrm{n}=699)=24.01, \mathrm{p}=0.00,\left(\mathrm{R}^{2}=0.06\right)\right.$. PTSD severity, however, was not related to cardiovascular problems $\left(\chi^{2}(1, \mathrm{n}=703)=\right.$ $\left.1.71, \mathrm{p}=0.19, \mathrm{R}^{2}=0.004\right)$, and thus was not examined in subsequent analyses.

\section{PTSD and physical health remain when controlling for demographic variables}

Individuals who were missing demographic data were excluded from subsequent analyses. In the gastrointestinal analyses, $39.6 \%$ $(n=280)$ of the participants were missing some demographic data and were therefore excluded from the analyses. In the musculoskeletal analyses, $39.0 \%(\mathrm{n}=276)$ of participants were missing some 
Table 1. Cross-tabulated results between physical health problems and PTSD

\begin{tabular}{|c|c|c|c|c|c|}
\hline \multicolumn{6}{|c|}{ Probable PTSD diagnosis n (\%) } \\
\hline & Present & Absent & $\chi^{2}$ & $\mathbf{p}$ & $\phi$ \\
\hline Gastrointestinal disorders & & & 0.96 & 0.33 & 0.04 \\
\hline Present & $63(9)$ & $34(5)$ & & & \\
\hline Absent & $363(51)$ & $245(35)$ & & & \\
\hline Musculoskeletal problems & & & 1.12 & 0.28 & 0.04 \\
\hline Present & $64(9)$ & $33(5)$ & & & \\
\hline Absent & $366(52)$ & $242(34)$ & & & \\
\hline Headaches & & & 0.96 & 0.33 & 0.04 \\
\hline Present & $63(9)$ & $34(5)$ & & & \\
\hline Absent & $363(51)$ & $245(35)$ & & & \\
\hline Cardiovascular problems & & & 1.31 & 0.25 & 0.04 \\
\hline Present & $33(5)$ & $64(9)$ & & & \\
\hline Absent & $244(35)$ & $364(52)$ & & & \\
\hline
\end{tabular}

demographic data, whereas in the headaches analyses $39.6 \%(\mathrm{n}=$ 280) were missing such data, and were excluded from the analyses. ANOVAs were conducted comparing excluded to included individuals on each dependent variable. Excluded and included individuals differed only on years served in the military in the joint/ rheumatological analysis $\left(\mathrm{F}(1,703)=4.29, \mathrm{p}<0.05, \mathrm{R}^{2}=0.006\right)$, which had a small effect. Demographic variables that were controlled included age, gender, income, marital status, length of deployment, and number of deployments.

In the gastrointestinal analysis, after controlling for demographics, the PTSD severity model was still significant $\left(\chi_{\text {change }}^{2}(1, \mathrm{n}=427)=22.75, \mathrm{p}=0.00, \mathrm{R}_{\text {change }}^{2}=0.09\right)$. The musculoskeletal and headaches analyses were also significantly related to PTSD severity after demographics were controlled $\left(\chi_{\text {change }}^{2}(1, \mathrm{n}=\right.$ $431)=4.64, \mathrm{p}=0.03, \mathrm{R}_{\text {change }}^{2}=0.02 ; \chi_{\text {change }}^{2}(1, \mathrm{n}=427)=14.69, \mathrm{p}=$ $0.00, R_{\text {change }}^{2}=0.06$, respectively). Table 2 provides a summary of these results.

\section{Discussion}

Results demonstrated that PTSD was related to gastrointestinal disorders, musculoskeletal problems, and headaches. This is consistent with previous military studies demonstrating a relationship between PTSD and these three health conditions [3,6,10,11]. These findings also mirror those of civilian samples as well $[7,9]$.

A number of different conceptual models have been proposed to explain PTSD's relationship with health status. One recent integrative model proposed that PTSD affects physical health through four different intermediary mechanisms: psychological (e.g. comorbid depression), biological (e.g. alteration of the hypothalamic-pituitary-adrenal system), attentional (e.g. somatization), and behavioural (e.g. self-medication) [25]. According to this model, PTSD influences these components (which in fact all may interact with each other), and in turn can affect physical health status. Thus, these four mechanisms may be considered to mediate the relationship between PTSD and health status. Future research should more comprehensively test for such mediation, based on this recent conceptual model.

The lack of a significant relationship between PTSD and cardiovascular problems was unexpected, because military studies have consistently demonstrated such a relationship $[3,4,6,10]$. One possible explanation for this lack of a relationship might be the inclusion of female participants in this sample. Women tend to have fewer cardiovascular problems than men [26], and including women might have led to a null PTSD-cardiovascular problem relationship. Also, because men over the age of 55 years and postmenopausal women are at a greater risk of heart disease $[27,28]$, the relative young age of the present sample (mean age $=44.87$ years) may have contributed to the lack of association between PTSD and cardiovascular problems. Another possible explanation is that this study utilized data from Veterans Affairs Canada, and Canadians have slightly lower rates of cardiovascular problems than US residents [26].

This study produced small effect sizes, and this is consistent with some of the relevant literature. Some studies have reported small to moderate effect sizes for PTSD's relationship with these four health 
Table 2. Relationship between PTSD severity and the three health conditions, after controlling for demographic factors (logistic regression)

\begin{tabular}{|c|c|c|c|c|c|c|}
\hline Regression analyses & $n(d f=1)$ & $\chi_{\text {change }}^{2}$ & $\mathbf{p}$ & $\mathbf{R}_{\text {change }}^{2}$ & Unadjusted OR & Adjusted OR \\
\hline \multicolumn{7}{|c|}{ Gastrointestinal disorders } \\
\hline Demographics & 427 & 7.32 & 0.23 & 0.03 & & \\
\hline PTSD & 427 & 22.75 & $<0.001^{\star \star \star}$ & 0.09 & 1.03 & 1.04 \\
\hline \multicolumn{7}{|c|}{ Musculoskeletal problems } \\
\hline Demographics & 431 & 13.68 & $0.03^{*}$ & 0.05 & & \\
\hline PTSD & 431 & 4.64 & $0.03^{*}$ & 0.02 & 2.65 & 1.02 \\
\hline \multicolumn{7}{|l|}{ Headaches } \\
\hline Demographics & 427 & 5.79 & 0.45 & 0.02 & & \\
\hline PTSD & 427 & 14.69 & $<0.001^{\star \star \star}$ & 0.06 & 0.20 & 1.03 \\
\hline
\end{tabular}

OR, odds ratio; PTSD, post-traumatic stress disorder; $\chi_{\text {change }}^{2}$ and $R_{\text {change }}^{2}$ indicate the change in values of $\chi^{2}$ and $R^{2}$ when adding demographics in step 1 , and in adding PTSD in step 2 of sequential regression analyses; ${ }^{*},{ }^{* \star *} p$ significant at the correct alpha level.

variables [3]. Other studies, however, have demonstrated moderate to large effect sizes for some of these relationships [10].

The present study found that PTSD was related to gastrointestinal disorders, musculoskeletal problems, and headaches when PTSD was treated as a continuous variable, but this relationship was not present when PTSD was treated as a dichotomous variable. When examining the relationship between PTSD and health conditions, previous studies have used both continuous measures and dichotomous measures. It is not unusual to have a decrease in effect size and power when converting a continuously scaled variable to a categorical variable [29]. Because the present study found a small effect size when PTSD was treated as a continuous variable, it is likely that the decrease in effect size from converting a continuous variable into a dichotomous variable resulted in the lack of significance for the dichotomous variable. Future studies examining PTSD's relation with medical problems should carefully consider the scale of the PTSD predictor variable and its potential implications for the results.

PTSD's relationship with the three health conditions was not affected by demographic variables. In the gastrointestinal and headaches analyses, demographics did not contribute any significant variance to the models. In the musculoskeletal analysis demographics contributed significantly to the model, but this did not significantly affect the relationship between PTSD and musculoskeletal problems. It should be noted, however, that participants with missing demographic data had to be excluded in these analyses. Although excluded and included participants differed negligibly on the study variables, it must be acknowledged that results could have been affected nonetheless. Thus, although controlling for demographic factors did not seriously affect results, the findings from these analyses should be interpreted cautiously because of subject exclusions.

Another potential limitation is the use of self-report measures, such as the PCL-M. Although these measures have been used extensively in previous research to identify PTSD [18-20,30], the diagnosis of PTSD in the present study was not confirmed by a diagnostic clinical interview. Furthermore, the selfreport of medical conditions can be considered as a limitation of the present study. The results cannot be generalized to military populations or veterans in general because we sampled only veterans who were pensioned for a service-connected medical disability. It should also be noted that due to the cross-sectional nature of the data, we cannot assume causation, but only correlation between PTSD and the four health conditions. Because the present study used an archival dataset that did not collect data on general mental health well-being, we could not examine if PTSD specifically was related to physical health, or if PTSD served as a proxy for mental health difficulties in general. Nonetheless, this paper contributes information on PTSD's health status associations among peacekeeping veterans, an important sample of trauma survivors. Future research should examine PTSD's relationship with other medical conditions that were not included in the present study, and conceptually driven models of the PTSD-health relationship recently proposed.

\section{Conclusions}

The present results have important clinical implications. Studies of veterans have demonstrated associa- 
tions between increased medical care utilization and psychiatric problems [17,31-33]. The observed association between PTSD severity and physical health problems stresses the importance of screening for both physical illness and PTSD in primary care settings, especially in patients with a history of military service.

PTSD and physical health problems are an important concern in the veteran population. The association between psychiatric illnesses such as PTSD and physical health problems is useful for clinicians and hospital administrators to better understand the potential medical and psychiatric needs of veterans. The observed association between PTSD and physical health further supports the need for an integrated primary care-psychiatric service delivery model to address the health-care needs of veterans.

\section{Acknowledgement}

J. Don Richardson is a consultant for Veterans Affairs Canada.

\section{References}

1. Dirkzwager AJE, Bramsen I, van der Ploeg HM. Factors associated with posttraumatic stress among peacekeeping soldiers. Anxiety Stress Coping 2005; 18:37-51.

2. Orsillo SM, Roemer L, Litz BT, Ehlich P, Friedman MJ. Psychiatric symptomatology associated with contemporary peacekeeping: an examination of post-mission functioning among peacekeepers in Somalia. J Trauma Stress 1998; 11:611-625.

3. Boscarino JA. Diseases among men 20 years after exposure to severe stress: implications for clinical research and medical care. Psychosom Med 1997; 59:605-614.

4. Boscarino JA, Chang J. Electrocardiogram abnormalities among men with stress-related psychiatric disorders: implications for coronary heart disease and clinical research. Ann Behav Med 1999; 21:227-234.

5. Schnurr PP, Jankowski MK. Physical health and posttraumatic stress disorder: review and synthesis. Semin Clin Neuropsychiatry 1999; 4:295-304.

6. Schnurr PP, Spiro A, Paris AH. Physician-diagnosed medical disorders in relation to PTSD symptoms in older male military veterans. Health Psychol 2000; 19:91-97.

7. Sledjeski EM, Speisman B, Dierker LC. Does number of lifetime traumas explain the relationship between PTSD and chronic medical conditions? Answers from the National Comorbidity Survey-Replication (NCS-R). J Behav Med 2008; 31:341-349.

8. Jakupcak M, Luterek J, Hunt S, Conybeare D, McFall M. Posttraumatic stress and its relationship to physical health functioning in a sample of Iraq and Afghanistan war veterans seeking postdeployment VA health care. J Nerv Ment Dis 2008; 196:425-428.

9. Sareen J, Cox BJ, Stein MB, Afifi TO, Fleet C, Asmundson GJG. Physical and mental comorbidity, disability, and suicidal behavior associated with posttraumatic stress disorder in a large community sample. Psychosom Med 2007; 69:242-248.

10. Boscarino JA. Posttraumatic stress disorder and physical illness: results from clinical and epidemiologic studies. Ann $N$ Y Acad Sci 2004; 1032:141-153.

11. McFarlane AC, Atchison M, Rafalowicz E, Papay P. Physical symptoms in post-traumatic stress disorder. J Psychosom Res 1994; 38:715-726.

12. Schnurr PP, Friedman MJ, Rosenberg SD. Premilitary MMPI scores as predictors of combat-related PTSD symptoms. Am J Psychiatry 1994; 151:156-157.

13. Wolfe J, Schnurr PP, Brown PJ, Furey JA. Posttraumatic stress disorder and war-zone exposure as correlates of perceived health in female Vietnam War veterans. $J$ Consult Clin Psychol 1994; 62:1235-1240.

14. Beckham JC, Moore SD, Feldman ME, Hertzberg MA, Kirby AC, Faribank JA. Health status, somatization, and severity of posttraumatic stress disorder in Vietnam combat veterans with posttraumatic stress disorder. Am J Psychiatry 1998; 155:1565-1569.

15. United Nations. How has peacekeeping evolved? New York: United Nations, 2006.

16. Hillen J. Blue helmets: the strategy of UN military operations. Washington, DC: Brassey's, 1998.

17. Richardson D, Elhai JD, Pedlar D. Association of PTSD and depression with medical and specialist care utilization in modern peacekeeping veterans in Canada with health-related disabilities. J Clin Psychiatry 2006; 67:1240-1245.

18. Asmundson GJG, Stein MB, McCreary DR. Posttraumatic stress disorder symptoms influence health status of deployed peacekeepers and nondeployed military personnel. J Nerv Ment Dis 2002; 190:807-815.

19. Barrett DH, Doebbeling CC, Schwartz DA et al. Posttraumatic stress disorder and self-reported physical health status among U. S. military personnel serving during the Gulf War period: population-based study. Psychosomatics 2002; 43:195-205.

20. Hoge CW, Castro CA, Messer SC, McGurk D, Cotting DI, Koffman RL. Combat duty in Iraq and Afghanistan: mental health problems and barriers to care. N Engl J Med 2004; 351:13-22.

21. Weathers FW, Litz BT, Herman DS, Huska JA, Keane TM. The PTSD Checklist: reliability, validity and diagnostic utility. In: Annual Meeting of the International Society for Traumatic Stress Studies, San Antonio, TX: International Society for Traumatic Stress Studies, 1993.

22. Weathers FW, Ford J. Psychometric review of PTSD Checklist (PCL-C, PCL-S, PCL-M, PCL-PR). In: Stamm BH, ed. Measurement of stress, trauma, and adaptation. Lutherville, MD: Sidran Press, 1996.

23. Aickin M, Gensler H. Adjusting for multiple testing when reporting research results: the Bonferroni vs Holm methods. Am J Public Health 1996; 86:726-728.

24. Holm S. A simple sequentially rejective multiple test procedure. Scand J Stat 1979; 6:65-70.

25. Schnurr PP, Green BL. Understanding relationships among trauma, post-traumatic stress disorder, and health outcomes. Adv Mind Body Med 2004; 20:18-29.

26. Pilote L, Dasgupta K, Guru V et al. A comprehensive view of sex-specific issues related to cardiovascular disease. CMAJ 2007; 176:S1-S44.

27. Heart and Stroke foundation of Ontario. Risk factors you can't control. Ottawa: Heart and Stroke Foundation of Canada, 2008.

28. Mackay J, Mensah G. Atlas of heart disease and stroke. Geneva: World Health Organization, 2004.

29. MacCallum RC, Zhang S, Preacher KJ, Rucker DD. On the practice of dichotomization of quantitative variables. Psychol Methods 2002; 7:19-40. 
30. Forbes D, Creamer M, Hawthorne G, Allen N, McHugh T. Comorbidity as a predictor of symptom change after treatment in combat-related posttraumatic stress disorder. J Nerv Ment Dis 2003; 191:93-99.

31. Elhai JD, Richardson D, Pedlar D. Predictors of general medical and psychological treatment use among a national Canadian sample of United Nations peacekeeping veterans. J Anxiety Disord 2007; 21:580-589.
32. Marshall RP, Jorm AF, Grayson DA, Dobson M, O'Toole BI. Help-seeking in Vietnam veterans: post-traumatic stress disorder and other predictors. Aust N Z J Public Health 1997; $21: 211-213$

33. Marshall RP, Jorm AF, Grayson DA, O'Toole BI. Posttraumatic stress disorder and other predictors of health care consumption by Vietnam veterans. Psychiatr Serv 1998; 49:1609-1611. 